Short Note

\title{
Color Properties of Eu-, Pr-doped and Codoped $\mathrm{CeO}_{2}$
}

\author{
Masaya AMIMOTO ${ }^{1}$ and Masakuni OZAWA ${ }^{2 *}$ \\ ${ }^{1}$ Tajimi City Pottery Design and Technical Center, Misaka-cho, Tajimi 507-0803, Japan. \\ ${ }^{2}$ Institute of Materials and Systems for Sustainability, Nagoya University, Nagoya 464-8603, Japan.
}

Received September 10, 2017; Revised October 17, 2017; Accepted October 20, 2017

\begin{abstract}
Eu- and Pr-doped and codoped ceria $\mathrm{Ce}_{1-\mathrm{x}-\mathrm{y}} \mathrm{Eu}_{\mathrm{x}} \mathrm{Pr}_{\mathrm{y}} \mathrm{O}_{2-\delta}(\mathrm{x}=0,0.01 ; \mathrm{y}=0,0.0005)$ powder samples were synthesized by a coprecipitation method. The samples were characterized by XRD, color measurement, and UV-Vis diffuse reflectance spectroscopy. X-ray diffraction data indicated the formation of solid solution with fluorite-type structure. Pr doping to $\mathrm{CeO}_{2}$ resulted in the brown color, although Eu-doped $\mathrm{CeO}_{2}$ showed the same yellow as $\mathrm{CeO}_{2}$. Eu- and $\mathrm{Pr}$-codoped ceria of $\mathrm{Ce}_{0.9895} \mathrm{Eu}_{0.01} \mathrm{Pr}_{0.0005} \mathrm{O}_{2-\delta}$ showed brown color and the color change under light irradiation. The UV-vis spectra suggested photochromic properties.
\end{abstract}

KEY WORDS

$\mathrm{CeO}_{2}$, praseodymium, europium, pigment, photochromic property

\section{Introduction}

Warm color pigments such as red to orange, yellow and brown attract attention among the needs for color variation, especially in Europe $^{1)}$. Many inorganic pigments are used for industrial products, such as potteries, dishes and other daily ceramics, which are manufactured by high-temperature firing. In the case of ceramic, they are required to have heat resistance so that color can be retained even by firing at elevated temperatures. However, present industrial yellow and warm color pigments for such application composed of cadmium sulfide, cadmium selenide, and antimony-lead etc. and they are toxic and low heat-resistant materials ${ }^{2-4)}$. Several researches tried to study the ceria $\left(\mathrm{CeO}_{2}\right)$-based pigments which show yellow and warm color, and attempted to adjust the color tone by mixing $\mathrm{CeO}_{2}$, zirconia $\left(\mathrm{ZrO}_{2}\right)$ and further rare earth element ${ }^{5-7)}$. Among rare earths, the addition of praseodymium (Pr) is often suitable for color adjustment in yellow to pink $^{8)}$, and europium $(\mathrm{Eu})$ in $\mathrm{CeO}_{2}$ can induce fluorescence emission ${ }^{9}$. In this work, we synthesized the pigments of $\mathrm{CeO}_{2}$ which is doped with both $\mathrm{Pr}$ and $\mathrm{Eu}$, and examined their optical properties. The development of warm color and a phenomenon of color (photochromic) change under light irradiation were newly observed in the present system of Eu-Pr- $\mathrm{CeO}_{2}$.

\section{Experimental}

The powders of composition; $\mathrm{CeO}_{2}, \mathrm{Ce}_{0.99} \mathrm{Eu}_{0.01} \mathrm{O}_{2-\delta}$, and $\mathrm{Ce}_{0.9895} \mathrm{Eu}_{0.01} \mathrm{Pr}_{0.0005} \mathrm{O}_{2-\delta}$ were synthesized by a coprecipitation method.

* Corresponding author, E-mail: ozawa@imass.nagoya-u.ac.jp
The starting materials $\mathrm{Ce}\left(\mathrm{NH}_{4}\right)_{2}\left(\mathrm{NO}_{3}\right)_{6}$ (Wako Pure Chemical Industries, 99.5\%), $\operatorname{Pr}\left(\mathrm{NO}_{3}\right)_{3} \cdot 6 \mathrm{H}_{2} \mathrm{O}$ (Wako Pure Chemical Industries, 99.5\%), and $\mathrm{Eu}\left(\mathrm{NO}_{3}\right)_{3} \cdot 6 \mathrm{H}_{2} \mathrm{O}$ (Soegawa Rikagaku, 99.9\%) were dissolved in distilled water and an ammonia aqueous solution was added to form a precipitate under agitation. After filtration and washing, the obtained gel-like precipitates were dried at $383 \mathrm{~K}$ and grinded. They were subjected to heat-treatment at $873 \mathrm{~K}$ for $3 \mathrm{~h}$ in air, and grinded to obtain powder samples.

A powder X-ray diffractometer (Rigaku Miniflex II) was used for evaluation of the crystal phase of powders. A color measurement meter (Konica Minolta CM-2600d) attached with a xenon lamp as a light source was used for evaluation of optical and color properties. The result of the colorimetric test is indicated by CIE $\mathrm{L}^{*} \mathrm{a} * \mathrm{~b}$ scale ${ }^{10)}$. Here, $\mathrm{L}^{*}$ indicates brightness, 0 is black and 100 is white. $a^{*}$ and $b^{*}$ represent coloring, $a^{*}$ represents green to red, the minus side is green, and the plus side is red. $\mathrm{b}^{*}$ represents blue to yellow, the minus side is blue and the plus side is yellow. UV-vis diffuse reflectance spectra were measured using an ultraviolet-visible spectrophotometer (Hitachi High-Technologies U-3000, light source: WI lamp and D2 lamp). In the evaluation of discoloration by light irradiation, the diffuse reflection spectrum was measured at the first, and then the colorimetric evaluation was done by every $10 \mathrm{~s}$ for $90 \mathrm{~s}$ after the first measurement. The diffuse reflectance spectrum was measured again and the color recovery phenomenon (when the sample was placed in the dark place in a spectrophotometer) was observed by the repeated spectra measurement for $1 \mathrm{~h}$ 


\section{Results and discussion}

Fig. 1 shows the X-ray diffraction patterns of the samples. Cubic fluorite type structures corresponding to $\mathrm{CeO}_{2}$ phase were observed in all samples. Additional phase by $\mathrm{Pr}$ and Eu doping could not be found, suggesting the formation of solid solutions. .

Fig. 2 shows the results of color measurement, where the CIE $\left(L^{*}, a^{*}, b^{*}\right)$ values of the color tone of each sample are plotted by using color coordinates of $\mathrm{L}^{*}$ and $\mathrm{a}^{*}-\mathrm{b}^{*}$ plane. Table 1 shows CIE $\left(L^{*}, a^{*}, b^{*}\right)$ values of color tone of each sample. The values of $\left(\mathrm{L}^{*}, \mathrm{a}^{*}, \mathrm{~b}^{*}\right)$ of $\mathrm{CeO}_{2}, \mathrm{Ce}_{0.99} \mathrm{Eu}_{0.01} \mathrm{O}_{2-\delta}, \mathrm{Ce}_{0.9895} \mathrm{Eu}_{0.01} \mathrm{Pr}_{0.0005} \mathrm{O}_{2-\delta}$ are $(95,-6,29),(95,-5,24)$ and $(83,4,15)$, respectively. $\mathrm{CeO}_{2}$ and $\mathrm{Ce}_{0.99} \mathrm{Eu}_{0.01} \mathrm{O}_{2-\delta}$ showed a color tone corresponding to a pale yellow color, and $\mathrm{Ce}_{0.9895} \mathrm{Eu}_{0.01} \mathrm{Pr}_{0.0005} \mathrm{O}_{2-\delta}$ showed reddish brown. Thus, $\mathrm{Pr}$ addition resulted in warming color-modification from yellow to slightly dark but reddish color tone in $\mathrm{CeO}_{2}$.

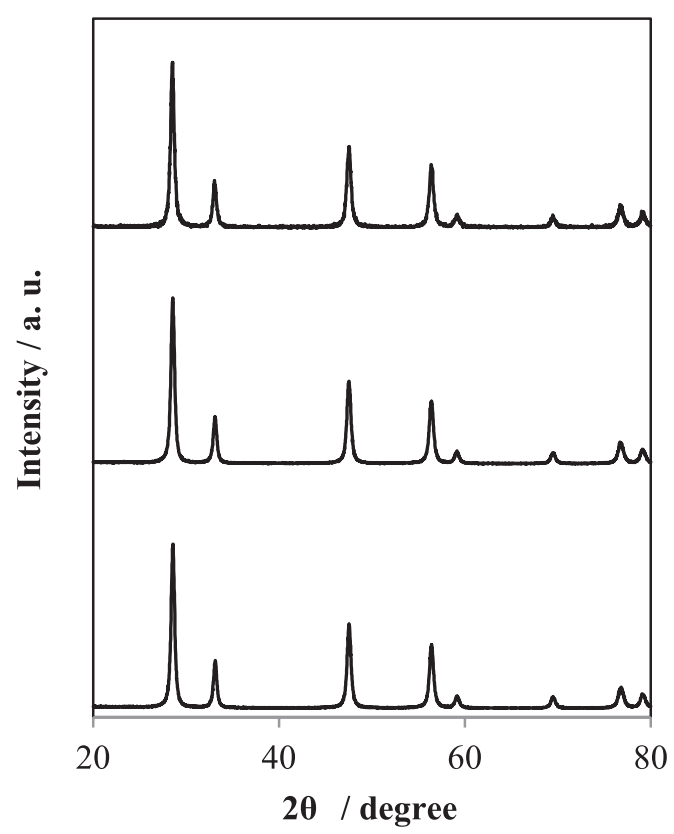

Fig. 1 XRD patterns of the $\mathrm{Ce}_{1-\mathrm{x}-\mathrm{y}} \mathrm{Eu}_{\mathrm{x}} \mathrm{Pr}_{\mathrm{y}} \mathrm{O}_{2-\delta}(\mathrm{x}=0,0.01 ; \mathrm{y}=0,0.0005)$ powder samples after heat treatment at $873 \mathrm{~K}$ for $3 \mathrm{~h}$. (a) $\mathrm{CeO}_{2}$, (b) $\mathrm{Ce}_{0.99} \mathrm{Eu}_{0.01} \mathrm{O}_{2-\delta},(\mathrm{c}) \mathrm{Ce}_{0.9895} \mathrm{Eu}_{0.01} \mathrm{Pr}_{0.0005} \mathrm{O}_{2-\delta}$.

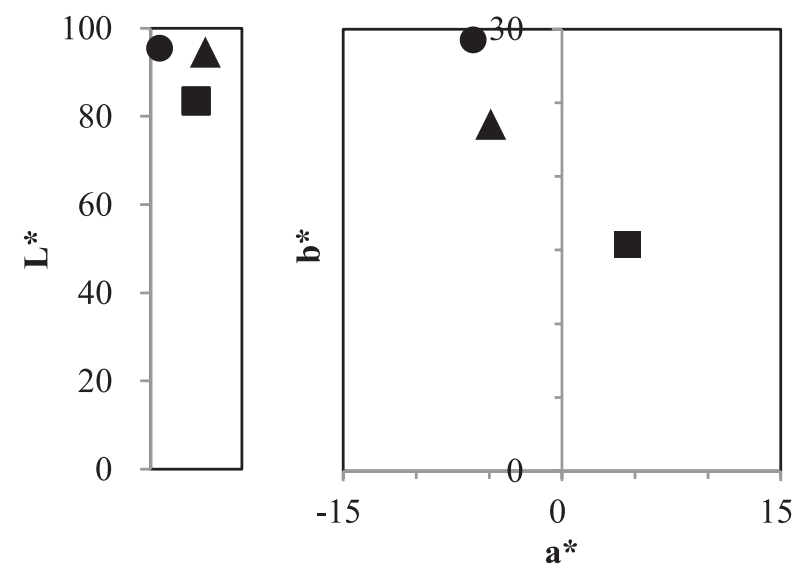

Fig. 2 The CIE $\mathrm{L}^{*} \mathrm{a} * \mathrm{~b} *$ colour space for $\mathrm{CeO}_{2}(\bullet), \quad \mathrm{Ce}_{0.99} \mathrm{Eu}_{0.01} \mathrm{O}_{2-\delta}(\boldsymbol{\Delta})$, $\mathrm{Ce}_{0.9895} \mathrm{Eu}_{0.01} \mathrm{Pr}_{0.0005} \mathrm{O}_{2-\delta}(\boldsymbol{\bullet})$ after heat treatment at $873 \mathrm{~K}$ for $3 \mathrm{~h}$.
Fig. 3 shows the color change experimental result of $\mathrm{Ce}_{0.9995} \mathrm{Eu}_{0.01} \operatorname{Pr}_{0.0005} \mathrm{O}_{2-\delta}$, which is indicated by the CIE (L*, $\mathrm{a}^{*}, \mathrm{~b}^{*}$ ) coordinates during the measurement. $\mathrm{Ce}_{0.99} \mathrm{Eu}_{0.01} \mathrm{O}_{2-\delta}$ without $\mathrm{Pr}$ showed no change in $\mathrm{L}^{*}, \mathrm{a}^{*}$ and $\mathrm{b}^{*}$ under the same condition, but $\mathrm{Ce}_{0.9895} \mathrm{Eu}_{0.01} \mathrm{Pr}_{0.0005} \mathrm{O}_{2-\delta}$ showed the decrease of all values of $\mathrm{L}^{*}$, $\mathrm{a}^{*}$ and $\mathrm{b}^{*}$. The color tone changed to brown with a greenish blue by light irradiation procedure. The temporal change in reflectance with UV-Vis showed clear change, as shown in Fig. 4, and was characterized by the decrease in the wavelength region of $>600 \mathrm{~nm}$. It is interesting to note that original color was recovered after stopping the light irradiation and leaving it under dark condition in a UV-Vis apparatus for $1 \mathrm{~h}$.

Table 1 The CIE $\mathrm{L}^{*} \mathrm{a} \mathrm{b}^{*}$ colour space for the $\mathrm{Ce}_{1-\mathrm{x}-\mathrm{y}} \mathrm{Eu}_{\mathrm{x}} \mathrm{Pr}_{\mathrm{y}} \mathrm{O}_{2-\delta}(\mathrm{x}=0$, $0.01 ; \mathrm{y}=0,0.0005$ ) powder samples after heat treatment at $873 \mathrm{~K}$ for $3 \mathrm{~h}$.

\begin{tabular}{lccc}
\hline & $\mathrm{L}^{*}$ & $\mathrm{a}^{*}$ & $\mathrm{~b}^{*}$ \\
\hline $\mathrm{CeO}_{2}$ & 95 & -6 & 29 \\
$\mathrm{Ce}_{0.99} \mathrm{Eu}_{0.01} \mathrm{O}_{2-\delta}$ & 95 & -5 & 24 \\
$\mathrm{Ce}_{0.9895} \mathrm{Eu}_{0.01} \mathrm{Pr}_{0.0005} \mathrm{O}_{2-\delta}$ & 83 & 4 & 15 \\
\hline
\end{tabular}

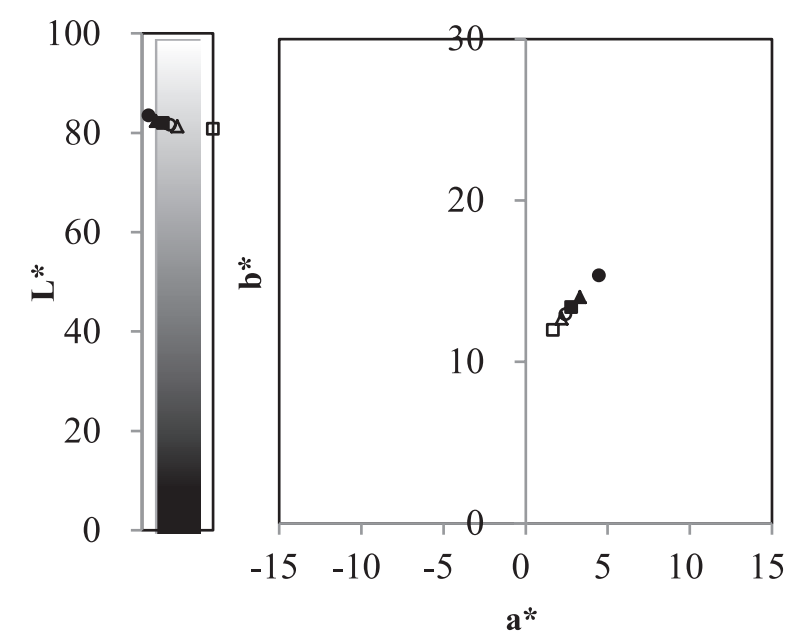

Fig. 3 Color change of $\mathrm{Ce}_{0.9895} \mathrm{Eu}_{0.01} \mathrm{Pr}_{0.0005} \mathrm{O}_{2-\delta}$ in CIE L*a*b* colour space during the color measurement. $\bullet ; 0 \mathrm{~s}, \mathbf{\Delta} ; 10 \mathrm{~s}, \mathbf{m} ; 20 \mathrm{~s}, \bigcirc ; 30 \mathrm{~s}, \Delta$; $40 \mathrm{~s}, \mathrm{f} ; 90 \mathrm{~s}$.

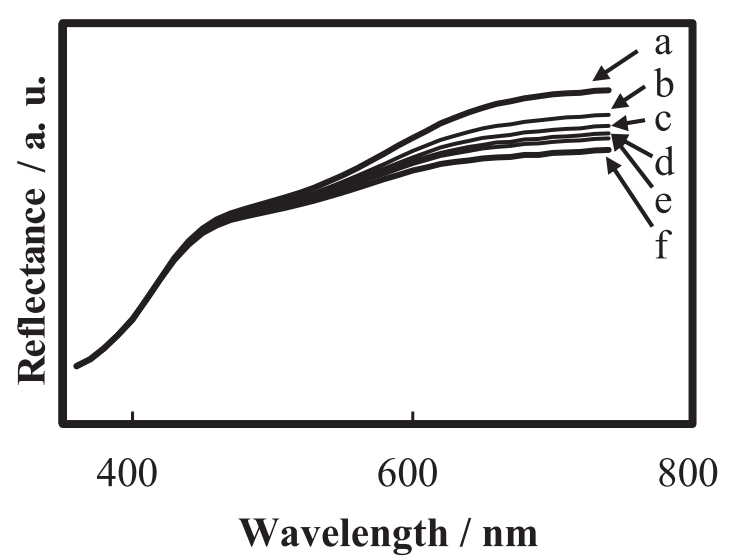

Fig. 4 Changes in reflectance spectra of $\mathrm{Ce}_{0.9895} \mathrm{Eu}_{0.01} \mathrm{Pr}_{0.0005} \mathrm{O}_{2-\delta}$. a; $0 \mathrm{~s}$, b; $10 \mathrm{~s}, \mathrm{c} ; 20 \mathrm{~s}, \mathrm{~d} ; 30 \mathrm{~s}, \mathrm{e} ; 40 \mathrm{~s}, \mathrm{f} ; 90 \mathrm{~s}$. 
This is the first report about color (photochromic) change under light irradiation in this system. Eu itself did not affect the color tone in $\mathrm{CeO}_{2}$, but after co-adding $\mathrm{Pr}$ and $\mathrm{Eu}$ a novel phenomenon of color change was induced in $\mathrm{CeO}_{2}$. The energy of the fluorescence emission from Eu center may play a role for change in electric density of Pr cation. It also seems that the color strongly depends on the valence state of these cations, although the mechanism of phenomenon is not completely resolved soon. It is considered that the cooperation and charge transfer in Eu-Pr complex center might make a novel color modifier site which is important to induce a photochromic phenomenon in this system.

\section{Conclusion}

A new warm-colored photochromic material was obtained in solid solutions, when $\mathrm{Eu}$ and $\mathrm{Pr}$ were introduced into $\mathrm{CeO}_{2} \cdot \mathrm{CeO}_{2}$ and $\mathrm{Ce}_{0.99} \mathrm{Eu}_{0.01} \mathrm{O}_{2-\delta}$ showed a color tone corresponding to a pale yellow color. $\mathrm{Ce}_{0.9895} \mathrm{Eu}_{0.01} \mathrm{Pr}_{0.0005} \mathrm{O}_{2-\delta}$ powder show reddish brown, and Pr was effective for warming color-modification from yellow to slightly dark but reddish color tone. The color changes of $\mathrm{Ce}_{0.9895} \mathrm{Eu}_{0.01} \mathrm{Pr}_{0.0005} \mathrm{O}_{2-\delta}$ was shown by the decrease in $\mathrm{L}^{*}$, a* and $\mathrm{b}^{*}$ under light irradiation. The color tone changed to brown with a greenish blue by light irradiation, and the original color was recovered under dark condition. The present $\mathrm{CeO}_{2}$-based pigments can be expected as the novel warm-coloring and photochromic inorganic material.

\section{Acknowledgments}

This work was supported by a Grant-in-Aid for Scientific Research (No. 17H03100) of the Japan Society for the Promotion of Science.

\section{References}

1) H. Takashima: Yakimono-to-Yu-no-Kagaku, Uchida-Rokakuho. Tokyo, (1994) 234-247.

2) E. Kato: J. Ceram. Assoc. Jpn., 66 (1958) C83-C88.

3) G. D. Nero, G. Cappelletti, S. Ardizzone, P. Fermo, S. Gilardoni: J. Europ. Ceram. Soc., 24 (2004) 3603-361.

4) M. Jansen, H. P. Letschert: Nature, 404 (2000) 980-982.

5) T. Masui, S. Furukawa, N. Imanaka: Chem. Lett., 35 (2006) 1032-1034

6) M. Amimoto, K. Kimura, M. Haneda, M. Ozawa: J. Jpn. Soc. Powder Powder Metallurgy, 59 (2012) 75-79.

7) M. Amimoto, M. Haneda and M. Ozawa: J. Soc. Mater. Sci., Jpn., 63 (2014) 432-436.

8) J. A. Badenes, J. B. Vicent, M. Llusar, M. A. Tena, G. Monros: J. Mater. Sci., 7 (2002) 1413-1419.

9) M. Ozawa, Y. Yoshimura, K. Kobayashi: Jpn. J. Appl. Phys., 56 (2017) 01AE07.

10) JIS Z 8781-4 (2013). 